\title{
Accessing the Equity Return Volatility Effect of East and South Asian Nations: The Econometrics Modelling Method
}

\author{
Jewel Kumar Roy, Ashutosh Kolte, Balkrishan Sangvikar, Avinash Pawar
}

\begin{abstract}
In financial management, the equity market performance is the critical element of equity market returns volatility wherever the shareholder's resilience around the instability subsists. The data is collected from the authenticated secondary sources for the analysis. This paper shows that the 2008economicpredicament, as well as the effect above proceeding developing financial prudence of the globe, is found in the equity return instability connation of developing financial prudence (2004-2015). By the GARCH model, it can be examined that as the information from the U.S.A. stock market news has an essential consequences on the earnings of the $S \& P$ 500 stock market index, the indices of the east, as well as south Asian nations, has also influenced by the news of U.S.A. The GARCH model is estimated for the U.S.A. stock market news has a substantial effect or not on East and South Asian nation's daily share market returns. The outcomes show that market earnings in the equity market in east and south Asian nations are incredibly reliant on their historical earnings. It is found that Tokyo Topic (4.8929) is a highly volatile stock index among the East and South Asian stock returns, and the low volatile stock index is DSEX (0.0068). The news of the U.S.A. stock market has affected the equity market of India, Japan, China, and Korea, which are included in the East and South Asian stock market. In all the country's share markets, found most significant variance in the equity income instability. This study is essential for the shareholders looking for the diversification in the portfolio, domestic institutional investors and foreign institutional investors.
\end{abstract}

Keywords: Conditional Variance, Equity Market Return, Financial Modelling, Global Financial Crisis, GARCH Model, Portfolio Diversification, Volatility Effect.

\section{INTRODUCTION}

Even from a historical perspective, global economic integration is a prime concern for the world. The integration of global economic, through the financial and money market, has been on a generally growing trend. Because of this growing inter linkage between the international markets in the modern period; the economic domain is not in a stable position which offers the most crucial threat of economic

Revised Manuscript Received on October 15, 2019.

Jewel Kumar Roy, Department of Finance and Banking, Jatiya Kabi Kazi Nazrul Islam University, Bangladesh

Ashutosh Kolte*, Department of Management Sciences, Savitribai Phule Pune University, India

* Correspondence Author

Balkrishan Sangvikar, Department of Management Sciences, Savitribai Phule Pune University, India

Avinash Pawar, Department of Management Sciences, Savitribai Phule Pune University, India. crisis from any market to the other markets. So in the modern economic system, the crises of finance have a vital part which has two common bases, search for higher return and associated risk, for these crises. Although the developed economies are the main reason for these financial crises, the rising economies and other developing nations are also affected. However, United Kingdom voted for BREXIT and the process to take the UK out of the European Union for this reason on 27th June 2016, Britain's pound and the Chinese Yuan falling to a nearly six-year low against the dollar. In August 2007, the US subprime crisis was responsible for the global financial crisis, which showed the world wide drop of major banks and the equity market. The influence of the subprime crisis of the U.S.A. was found in the Japanese share market, which was the single major advanced economy that justifies the highly volatile stock index return between 2007 and 2008. The stock market declined by $56 \%$ and $71 \%$ for Hong Kong and China, respectively. From October 2007 to October 2008 were linked to the decline in the most critical economies shares. Because of the US financial crisis, the most affected South Asian stock markets were Indian stock markets, and these markets declined $60 \%$ in the index. Among the many serious global financial crisis, the US subprime crisis in 2007 was tremendously affected the economy because of the relationship in the middle of world-wide share values and unexpected set back of investment stream. As the intensity of this predicament had an adverse outcome on the instability pattern of share value return which varies from nation to nation rounded on their economic structure as well as equity markets, over the last few years where the researchers and analyst has been receiving considerable attention to use the modelling and forecasting volatility of equity market returns as a critical issue for the global financial market.

The stakeholders in the equity market places are attracted to identify how the instability of these variables, for example, equity returns changes with a period because if a share price is unstable then it brings more and more risk. The investors are taking a risk and investing time and money in the stock market; investors are familiar with the term of more risk more gain. Notably, different kind of investors are entering the stock markets with their diverse target, several as real investors, several as gambler and several as don't know anything about market their primary aim of looking for arbitrage opportunity; but market instability is one of the further most critical factors for everyone to catch into account by their investment. Volatility is a vital part of the living stock market because, without the 
volatility of the market, investors are not interested in investing their investment in the market, but too much bubble is not suitable for investors. The principal objective of this study is thus to observe the instability of the East as well as South Asia equity markets. For many economic and financial applications, the purpose of volatility is an essential part, and they have a core purpose of estimating instability is the risk management of the portfolio, optimal asset allocation, and captivating bets on upcoming instability.

The analysis of financial volatility can be estimated through the $\mathrm{E}$ views application in order to improve risk management and instability of the equity market index. This paper targets to learn the trends in equity market indices unpredictability and examine the major effect of news commencing the U.S.A. equity market on the instability of equity market of East and South Asian nations by GARCH type models where the daily index returns series of 2004 to 2015 has been observed. The uniqueness of this study is to use of volatility investigation to the markets in the East and South Asian nations. Not a single study has concentrated on the East and South Asian equity markets together, and after literature reviews, we found that a small number of papers have used GARCH $(1,1)$ volatility models which include probable instability news belongings to shack bright on the active connections by the U.S.A. equity market. The study is accepted by smearing a GARCH model which precedes the risk of irregular volatility possessions into justification too which we correspondingly model the average earnings. It facilitates the inter-dependence amongst the markets in the East and South Asian nations' instability of equity earnings.

The stock exchanges of different nations and their particular indices comprised and studied in the paper and information collected from the specific stock exchange websites are indicated in Table 1 as below.

Table 1: Countries with their stock indices

\begin{tabular}{|c|c|c|c|c|c|c|}
\hline Region & Nations & Stock Exchange & $\begin{array}{l}\text { Start } \\
\text { Year }\end{array}$ & $\begin{array}{c}\text { Selected } \\
\text { Index }\end{array}$ & Contraction & $\begin{array}{c}\text { Listed } \\
\text { Companies }\end{array}$ \\
\hline \multirow{4}{*}{$\begin{array}{l}\text { South } \\
\text { Asia }\end{array}$} & India & Bombay Stock Exchange & 1875 & BSE Sensex & BSESENSEX & 5,749 \\
\hline & Bangladesh & Dhaka Stock Exchange & 1954 & DSEX & DSEX & 559 \\
\hline & Pakistan & $\begin{array}{c}\text { Karachi Stock Exchange } \\
\text { Limited }\end{array}$ & 1947 & KSE 100 Index & KSE100 & 578 \\
\hline & Sri Lanka & $\begin{array}{l}\text { Colombo Stock } \\
\text { Exchange }\end{array}$ & 1896 & $\begin{array}{l}\text { S\&P Sri Lanka } 20 \\
\text { Index }\end{array}$ & S\&P SL 20 & 296 \\
\hline \multirow{5}{*}{$\begin{array}{l}\text { East } \\
\text { Asia }\end{array}$} & Hong Kong & Hong Kong Exchanges & 1997 & $\begin{array}{c}\text { S\&P HK Ex Large } \\
\text { Cap }\end{array}$ & $\begin{array}{l}\text { S\&P HK Ex } \\
\text { Large Cap }\end{array}$ & 1,680 \\
\hline & China & $\begin{array}{l}\text { Shanghai Stock } \\
\text { Exchange }\end{array}$ & 1990 & $\begin{array}{c}\text { SSE } \\
\text { Composite }\end{array}$ & $\begin{array}{c}\text { SSE } \\
\text { COMPOSITE }\end{array}$ & 1,113 \\
\hline & Korea & Korea Exchange & 2005 & KRX 100 & KRX100 & 2,075 \\
\hline & Taiwan & $\begin{array}{c}\text { Taiwan Stock Exchange } \\
\text { Corporation }\end{array}$ & 1961 & $\begin{array}{c}\text { Taiwan } \\
\text { Capitalization Wt } \\
\text { Stock Index }\end{array}$ & TAIEX & 809 \\
\hline & Japan & Tokyo Stock Exchange & 1878 & Tokyo Topix & TokyoTopix & 3,531 \\
\hline
\end{tabular}

\section{LITERATURE REVIEW}

Accepting the manners and causes of instability are serious for estimating internal securities, for executing international hedging policies and asset allocation planning, as well as designed for estimating supervisory suggestions to control global investment streams. The paper aims to observe the essential factors affecting the return instability in the market of East and South Asian countries. Specially, we emphasise how and to what point unpredictability in the East and South Asian nations markets are impacted by overseas shocks from the U.S.A. equity market news. Numerous studies have analysed the connection between equity returns and equity volatility. However, only limited papers emphasised on the dimensions of returns of share indices during the economic crisis. It is realised from the literature that most of the research has been supported the framework of the developed nations. As a result, it is essential to measure and understand the effects of sub-prime crisis of U.S.A. happened in the year 2008 based on the indices of equity return of developing markets like East and South Asian nations in the frame of the crisis and regaining time. Merely, rarer studies have examined the connection between advanced and emergent economies (Vento \& La Ganga, 2009).

It is observed that the level to which a group of East and South Asian emergent 
economics has become unified with the advanced economies, denoted by the comprehensive South East Asia market, throughout the sample period from 2004 to 2015 with day-to-day figures. The research of Bekaert \& Harvey (1997) concentrated on emergent market volatility and initiated that the market situation influences the volatility. It is realised that the impact on volatility is due to markets where global issues affect the volatility if it is entirely unified markets and native issues impact the volatility if it is segmented markets. It displays a relationship among developed and developing capital markets which are diverse in nature. However, the relationship of both the markets shows an increasing volatility of local markets in capital markets. Furthermore, the researchers Liu, Pan, \& Shieh (1998) observed the framework of global spreads in day-to-day proceeds for 06 domestic share markets; their outcomes show that the U.S.A. market is acting a leading part in manipulating Japan in an international context. Singapore, as wells as Pacific-Basin markets, has a noteworthy determined effect on the remaining Asian markets. However, the markets of Taiwan and Thailand are not having a well-organised system of processing international news.

Groenewold, Tang, \& Wu (2003) established that lower competence in the system of certainty of earnings on the root of their historical prices affects the promising for a robust investment structure. Based on the understanding of numerous previous research, it displays that China is the most substantial investment sector in Asia. In terms of evaluation of the effect on markets. The contribution of Lim, Brooks, \& Kim (2008) explored that the Asian developing markets were stable and functioning well again in the economic post-crisis era related to market competence and the shareholder's returns. It is realised that these markets not only respond to indigenous news but also trail as per the international news of other progressive markets.

Hammoudeh \& Li (2008)expressed about the unexpected ups and downs in volatility for Gulf equity markets is unpredictable and complex as the international news moves faster to them than native news. The study displays international crises from the period of 1994 to 2001 are accountable for enormous modifications in the volatility of Gulf equity markets. Furthermore, the analysis and interpretation of the selected markets are computed with GARCH $(1,1)$ models. On similar lines, Chiang \& Li (2007) applied the multivariate GARCH framework and initiated that the economic crisis time is an intensification in the relationships of financial variables. They denoted it as a contagion effect, and a sustained to identify the extraordinary connection in the few months of the crisis which symbolised higher movements in the markets. The methodological approach of Aggarwal, Inclan, \& Leal (1999) examined the effect of 1987 crash from the study of $\operatorname{GARCH}(1,1)$ using the econometric model, which grows into a universal event and creates a note worthy modification in the unpredictability of developing equity markets. By making an allowance for modernisations from the U.S.A. subprime crisis, this study investigates the effect of market news of U.S.A on the return volatility of a specific East and South
Asian market and evaluating the remaining part clarified by a home-grown dynamism.

Yilmaz (2010) emphasised on the U.S.A. sub-prime crisis 2008 that support to become the place for the volatility of equity returns in East Asian nations and the consideration was observed in the current international economic impact in the equity market. Subsequently, Syllignakis \& Kouretas (2011) found that the relationship among the Central and Eastern European markets, which were exaggerated by the sub-prime crisis of U.S.A. happened in 2008. However, there was no significant impact of this crisis on the German market. Accordingly, Samarakoon (2011) defined the outcome of interdependence and the contamination in the U.S.A. and overseas markets. Mostly, the conduction of shocks is found coinciding and non-coinciding markets as per the surprise initiatives of interdependence by U.S.A, however, on the other side; it has affected the developing markets with surprise initiative contagion. It is initiated that contagion can materialise from developing markets to the U.S.A. markets. Nevertheless, there is no contagion from the U.S.A. to developing markets. Accordingly, the shocks of U.S.A. markets conditions cannot disrupt more developing markets. In the context of developing nations, it initiates that, the current universal economic crisis suspiciously obstructed the mean returns and suspicious data reasons with superior volatility effect than expectant news in the Indian equity markets (Sakthivelet al. 2014).

Based on literature related to the financial crisis, this paper primarily examines the association among the technologically advanced markets. It also focused on relationships between developing markets and other overseas markets. It is essential to measure and deliberate the relationships within the Asian region and other emergent financial markets. It initiates proof for different causatives shapes on a national and global economies during the U.S.A. crisis. The existence of changes on the way to a higher than before relationship and variability are perceived encountered with marginal benefits. It is essential to understand the factors affecting East and South Asian indices On the basis of review of literature and research goal, the researchers propose the hypothesis (H01) that the East and South Asian Indices returns are not stationary or got unit root. The methods, analysis and testing of the hypothesis are performed in the data analysis section as per the objectives of this paper.

\section{RESEARCH METHOD}

The primary objective of this research study is to understand how the uncertain market volatility built on the returns of market Indices of East and South Asian equity markets. Further, it validates the appropriate to use a higher-order GARCH model to fitment for those indices. It also discovers the trends in the volatility of equity market indices of East and South Asian nations and analyses the significant effect of news from the S\&P 500 Index on the unpredictability of stock exchanges. The study is principally constructed on secondary data and information series from the databank maintained by East and South Asian Stock Exchanges

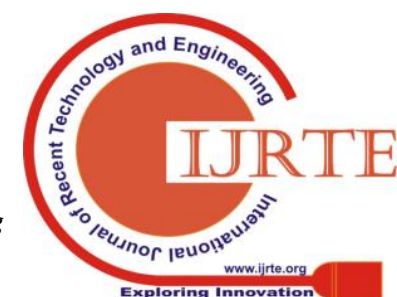


and websites of data stream international. This paper investigates the day-to-day information on stock indices return of Bangladesh, China, Hong Kong, India, Japan, Korea, Pakistan, Sri Lanka, Taiwan, and for the abovementioned period. These data are considered for emerging stock markets of East and South Asia and developed stock markets. All the indexes are denominated by countrywide currencies, and the means of the information of the preceding date and afterwards date has been considered. This study supports the daily adjusted closing value of the East and South Asian nations Stock Indices concluded the dated12years starting from 01/01/2004 to 30/09/2015. Firstly, work with full sample times then secondly we break up these sample times as per the time segments as pre-crisis, in-crisis, and post-crisis period. The information was used to compute returns summary indicators and for assessment of the GARCH model.

\section{ANALYSIS AND RESULTS}

\section{A) Index Sample Plot:}

Based on data of all stock indices, the researchers have developed the index sample period plot for all indices for the period of the study.

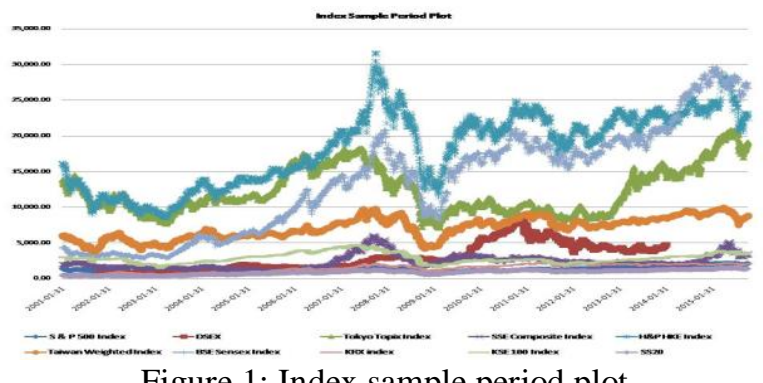

Figure 1: Index sample period plot

Furthermore, the day-to-day equity returns were calculated by considering the major dissimilarity of the ordinary logarithm of the share index for every single market with the calculation as per the following.

$\operatorname{RS}(\mathrm{i}, \mathrm{t})=\operatorname{Ln} \frac{\mathrm{P}(\mathrm{i} i \mathrm{t})}{\text { Pit }-1}$

\section{Whereas,}

$\mathrm{RS}_{(\mathrm{i}, \mathrm{t})}=$ return of stock indices for country $\mathrm{i}$ at time $\mathrm{t}$. Ln $\mathrm{P}_{(\mathrm{i}, \mathrm{t})}=$ natural logarithm the daily stock indices for country $i$ at time $t$.

The day-to-day share market returns $\left(\mathrm{R}_{\mathrm{t}}\right)$ based on specific East and South Asian indices were designed by consideration of logarithmic dissimilarity in the East and South Asian stock indices.

$R_{t}=\ln \left(\frac{\mathrm{I}_{\mathrm{t}}}{\mathrm{I}_{\mathrm{t}-1}}\right) \times 100$

Whereas, $I_{t}$ and $I_{t-1}$ are the closing value of daily East and South Asian stock tables at period "t"and "t-1"correspondingly. $I_{t}$ is the current indices value and $\mathrm{I}_{\mathrm{t}-1}$ is the preceding day's table's price.

\section{B) The Generalized Autoregressive Conditional Heteroscedasticity (GARCH) Model:}

The GARCH models have developed as the most prominent tools for assessing volatility as they are sufficient to capture the casualmovement of the economic information series. Numerous investigators have considered over time the act of GARCH models on amplification of thevolatility of established share markets. However, only a few have tested GARCH models using day-to-day figures from East and South Asia major share markets. The emphasis of our study is on estimating stock market volatility in S.E.A. major markets, which has not been systematically examined. The stock price volatility is valued using the appropriate type of GARCH model, which is primarily beneficial to analyse the economic data. Further, it was verified its significance in assessing the financial volatility in developed and emerging markets. In terms of statistics, the volatility represents a strong autocorrelation in squared returns which is perceived through Heteroscedasticity tests. As per the Bellerslev (1986), the comprehensive form of Heteroscedasticity is authorized as the generalised autoregressive conditional heteroskedasticity $(\mathrm{GARCH})$ that supports in evaluating the volatility using GARCH ( $\mathrm{g}, \mathrm{q})$ model that considers the following structure.

$\sigma_{t}^{2}=\alpha_{0}+\sum_{i=1}^{p} \alpha_{i} \epsilon_{t-i}^{2}+\sum_{i=1}^{q} \beta_{i} \sigma_{t-i}^{2}$

The GARCH model internments the inclination for assessing and evaluating the clusters of time series data for volatility indices. This framework supports identifying the behaviour of earnings based on the historical values of all types of variables in the study (Engle, 2002).It provides the thoughtful approach of correlation among the data, indexes and volatility. The methodology involved in the GARCH model consists of 3 phases. The first phase is to assess a fitment of the autoregressive model, then calculate the autocorrelations of the error terms, and finally, evaluate with the test for significance.

The following is the GARCH $(1,1)$ model for day-to-day equity return.

$\Upsilon_{t}=a+b \Upsilon_{t-1}+\varepsilon_{t}$

Variance equation is known as:

$\mathrm{ht}=\omega+\alpha_{1} \varepsilon \mathrm{t}-12+\beta_{1} \mathrm{ht}-1$

Whereas,

- $\omega>0, \alpha 0, \beta 1 \mathrm{ht}-1$

- ht is the conditional variance and ht- 1 is the conditional variance as per the historical data

By using GARCH model, It is easy to understand and calculate the currently fitted variance (ht) for the extended period, heteroskedasticity model mean value (dependent on $\omega)$, the volatility of the data for the period as per the prior date $\left(\alpha_{1} \varepsilon \mathrm{t}-12\right)$ and the fitted variance from the model during the for the period of the prior dated $\left(\beta_{1} h t-1\right)$. The stationarity situation for $\operatorname{GARCH}(1,1)$ is $\alpha_{1}+\beta_{1}<1$. The stationarity of the information is verified using the Augmented Dickey 
Fuller test. While the least possible Akaike statistics criteria is considered to define the number of lags.

There is an attempt to measures the influence of the U.S.A. share market news on the equity returns for the East and South Asian share markets using the GARCH model. In our paper, we observed the dynamic correlation between S.E.A. markets, U.S.A. equity market returns and volatilities in markets using a GARCH $(1,1)$ approach. Before analysinginformation, stationarity of time series data is assessed through the Augmented Dickey-Fuller test. In this consideration, the researchers have chosen the values of returns of the indices usingnatural log returns of every index.
Consequently, for the execution of the econometricapproach in the study, it is vital to ensure that the series less than the reference is stationary. The log of the ten series has been considered. In this manner, nine new variables are created which represent the return on BSE Sensex, DSEX, KRX 100, KSE 100 Index, S\&P Sri Lanka 20 Index, SSE Composite, S\&P HKEx Large Cap, Tokyo Topix, and Taiwan Capitalization Weighted Stock Index respectively.

\section{C) Stock Indices Analysis:}

Table 2: Statistical indices of stocks

\begin{tabular}{|c|c|c|c|c|c|c|c|c|c|}
\hline $\begin{array}{l}\text { Analytical } \\
\text { Tools }\end{array}$ & DSEX & Sensex & KSE & $\begin{array}{c}\text { S\&P } \\
\text { SL } \\
\text { SS20 }\end{array}$ & $\begin{array}{c}\text { SSE } \\
\text { COMPOS } \\
\text { ITE }\end{array}$ & HKEX & $\begin{array}{c}\text { Tokyo } \\
\text { TOPIX }\end{array}$ & $\begin{array}{c}\text { KRX } \\
100\end{array}$ & TAIEX \\
\hline$\tilde{\mathbf{x}}$ & 0.000225 & $\begin{array}{c}0.0002 \\
19 \\
\end{array}$ & $\begin{array}{c}0.0003 \\
01\end{array}$ & $\begin{array}{c}0.000 \\
198 \\
\end{array}$ & 0.000104 & $\begin{array}{c}9.79 \mathrm{E}- \\
05\end{array}$ & $\begin{array}{c}3.40 \mathrm{E}-0 \\
5\end{array}$ & $\begin{array}{c}0.00011 \\
6\end{array}$ & $\begin{array}{c}0.00018 \\
3 \\
\end{array}$ \\
\hline Median & 0.000263 & $\begin{array}{c}0.0003 \\
85\end{array}$ & $\begin{array}{c}0.0004 \\
79\end{array}$ & $\begin{array}{c}6.86 \mathrm{E} \\
-05\end{array}$ & 0.000119 & $\begin{array}{c}0.0002 \\
78\end{array}$ & $\begin{array}{c}0.00018 \\
7\end{array}$ & $\begin{array}{c}0.00030 \\
6\end{array}$ & $\begin{array}{c}0.00066 \\
1\end{array}$ \\
\hline Maximum & 0.088518 & $\begin{array}{c}0.0523 \\
50\end{array}$ & $\begin{array}{c}0.0358 \\
50\end{array}$ & $\begin{array}{c}0.046 \\
869\end{array}$ & 0.039235 & $\begin{array}{c}0.0579 \\
89\end{array}$ & $\begin{array}{c}0.05615 \\
0\end{array}$ & $\begin{array}{c}0.04988 \\
0\end{array}$ & $\begin{array}{c}0.06742 \\
2\end{array}$ \\
\hline Minimum & 0.040520 & $\begin{array}{c}0.0494 \\
38\end{array}$ & $\begin{array}{c}0.0553 \\
40\end{array}$ & $\begin{array}{c}0.036 \\
54\end{array}$ & 0.040199 & $\begin{array}{c}0.0584 \\
52\end{array}$ & $\begin{array}{c}0.04446 \\
3\end{array}$ & $\begin{array}{c}0.04570 \\
1\end{array}$ & $\begin{array}{c}0.06678 \\
9\end{array}$ \\
\hline$\sigma$ & 0.006773 & $\begin{array}{c}0.0071 \\
13 \\
\end{array}$ & $\begin{array}{c}0.0058 \\
18 \\
\end{array}$ & $\begin{array}{c}0.004 \\
659 \\
\end{array}$ & 0.007399 & $\begin{array}{c}0.0066 \\
71\end{array}$ & $\begin{array}{c}0.00622 \\
9 \\
\end{array}$ & $\begin{array}{c}0.00602 \\
2 \\
\end{array}$ & $\begin{array}{c}0.01250 \\
5 \\
\end{array}$ \\
\hline Skewness & 0.792581 & $\begin{array}{c}0.4514 \\
66\end{array}$ & $\begin{array}{c}0.6924 \\
37\end{array}$ & $\begin{array}{c}0.175 \\
672\end{array}$ & 0.453557 & $\begin{array}{c}0.0009 \\
01\end{array}$ & $\begin{array}{c}0.39789 \\
0\end{array}$ & $\begin{array}{c}0.38212 \\
0\end{array}$ & $\begin{array}{c}0.32077 \\
1\end{array}$ \\
\hline Kurtosis & 20.12827 & $\begin{array}{c}9.7928 \\
47\end{array}$ & $\begin{array}{c}8.5349 \\
05\end{array}$ & $\begin{array}{c}16.56 \\
506\end{array}$ & 6.919020 & $\begin{array}{c}12.364 \\
36\end{array}$ & $\begin{array}{c}10.2106 \\
9\end{array}$ & $\begin{array}{c}9.41755 \\
0\end{array}$ & $\begin{array}{c}6.62710 \\
6\end{array}$ \\
\hline Jarque Bera & 33595.89 & $\begin{array}{c}5709.3 \\
18\end{array}$ & $\begin{array}{c}3877.8 \\
82\end{array}$ & $\begin{array}{l}1861 \\
2.90\end{array}$ & 1986.289 & $\begin{array}{c}10519 . \\
29\end{array}$ & $\begin{array}{c}6313.08 \\
8\end{array}$ & $\begin{array}{c}5073.19 \\
5\end{array}$ & $\begin{array}{c}1645.05 \\
7\end{array}$ \\
\hline $\begin{array}{c}\text { Prob. of JB } \\
\text { test }\end{array}$ & 0.000000 & $\begin{array}{c}0.0000 \\
00\end{array}$ & $\begin{array}{c}0.0000 \\
00\end{array}$ & $\begin{array}{c}0.000 \\
000\end{array}$ & 0.000000 & $\begin{array}{c}0.0000 \\
00\end{array}$ & $\begin{array}{c}0.00000 \\
0\end{array}$ & $\begin{array}{c}0.00000 \\
0\end{array}$ & $\begin{array}{c}0.00000 \\
0\end{array}$ \\
\hline Observations & 2725 & 2918 & 2859 & 2426 & 2946 & 2879 & 2879 & 2915 & 2911 \\
\hline
\end{tabular}

Table 3 signifies the vivid information for the returns of every stock series for the daily sample dated. The yearly earnings of $\tilde{\mathrm{x}}$ (mean) and $\sigma$ (standard deviation) and the record of daily data are considered for evaluating the skewness and kurtosis. The outcomes indicate that the yearly means for earnings of the stock, with the exclusion of the earnings for Sri Lanka, are optimistic; on the other hand, they are very insignificant related to measure the equity risk by the standard deviation. The volatility is typically very extraordinary in developing equity markets; on the other hand, maximum in the Southeast Asian markets. As restrained by yearly computation of standard deviation, it is the maximum in Taiwan (0.012505) than China (0.007399) and the lowermost in Sri Lanka (0.004659) than Pakistan (0.005818). The mainstream of these equity earnings have negative skewness and positive kurtosis, here these mean, probably the normal distribution of the equity earnings will not be taken placed. The skewness of East Asian countries (such as China, Japan, Korea, and Taiwan) and South Asian countries (such as India, and Pakistan) equity returns is adverse but Taiwan market is vividly more adverse, which is steady with most advanced nations, however Bangladesh, Hong Kong, andSri Lanka equity earnings are optimistic, which is steady with several developing markets in this study, but Hong Kong is more robust market in Asia. All the stock returns are leptokurtic as perceived in the excess kurtosis, demonstrating that the generalized autoregressive conditional heteroskedasticity $(\mathrm{GARCH})$ models can be used for valuing these sequences. As a final point, all sequences are extremely auto correlated as well as consequently diverse auto regressive terms are use dagreeing to autocorrelation purposes. On the other hand, subsequently the unexpected modifications in the U.S.A. market updates are encompassed in the GARCH model, the consistent residuals present the considerably lesser skewness and kurtosis values. In addition, the Jarque-Bera test robustly rejects the status quo of the equity earnings sequences for the considered periods.

\section{D) Hypothesis Testing:}

To test the hypothesis of the study, the researchers have utilised the Augmented Dickey-Fuller (ADF) test for a unit root in a time series sample. The analysis is computed using a tool of numerical analysis for excel, which is a time series analysis add-in for Microsoft Excel developed by Spider Financial. Hence, NumXL affords 
a wider range of statistical tests and time series (linear and nonlinear) analysis tools. Furthermore, the ADF unit root test is used to evaluate the stationary of the time series data. The ADF unit root test is implemented by approximating the regression values as below.

$\Delta \mathrm{Yt}=\alpha 0+\alpha 1(\mathrm{Yt}-1)+\sum \gamma \mathrm{j}(\Delta \mathrm{Yt}-\mathrm{j})+\varepsilon \mathrm{t}$

In order to examine the hypothesis of the study, the Augmented Dickey-Fuller (ADF) unit root test is used. The hypothesis deliberates as $\mathrm{H} 01$ : Yt is not $\mathrm{I}(0)$. The values of the ADF signify the testing of hypothesis. If it is less than the critical value, then the null hypothesis is rejected, and the alternate is accepted. In the direction to understand the stationarity of the time series of the data in the study, the researchers have adopted the test for the presence of a unit root. The tests for unit root are the ADF test which integrates a procedure to realise the unit root and deterministic trend. Hypothesis (H01) considers that the East and South Asian Indices returns are not stationary or acquired unit root. The $\mathrm{ADF}$ test is executed to derive the values and test the hypothesis below.

Table 3: The ADF test for stock market indices

\begin{tabular}{|c|c|c|c|c|c|c|c|c|}
\hline \multirow[b]{2}{*}{ Region } & \multirow[b]{2}{*}{ Country } & \multirow[b]{2}{*}{ Indices } & \multirow{2}{*}{$\begin{array}{c}\text { ADF-Test } \\
\text { Statistics } \\
Z(t)\end{array}$} & \multicolumn{5}{|c|}{ Critical Values } \\
\hline & & & & $1 \%$ & $5 \%$ & $10 \%$ & p-value & $\begin{array}{c}\text { DW } \\
\text { Statistics }\end{array}$ \\
\hline \multirow{4}{*}{$\begin{array}{c}\text { South } \\
\text { Asia }\end{array}$} & Bangladesh & DSEX & -50.5698 & -3.4324 & -2.8623 & -2.5672 & 0.0001 & 1.9976 \\
\hline & India & BSE Sensex & -57.0095 & -3.4324 & -2.8623 & -2.5672 & 0.0001 & 2.0004 \\
\hline & Pakistan & KSE 100 & -46.5623 & -3.4324 & -2.8623 & -2.5672 & 0.0001 & 2.0089 \\
\hline & Sri Lanka & S\&P SL 20 & -41.2441 & -3.4329 & -2.8623 & -2.5672 & 0.0001 & 2.0117 \\
\hline \multirow{5}{*}{$\begin{array}{l}\text { East } \\
\text { Asia }\end{array}$} & China & SSE Composite & -24.8346 & -3.4324 & -2.8623 & -2.5672 & 0.0001 & 2.0012 \\
\hline & Hong Kong & $\begin{array}{l}\text { S\&P HKEx } \\
\text { Large Cap }\end{array}$ & -54.8119 & -3.4324 & -2.8623 & -2.5672 & 0.0001 & 1.9986 \\
\hline & Japan & Tokyo Topix & -53.7515 & -3.4324 & -2.8623 & -2.5672 & 0.0001 & 2.0016 \\
\hline & Korea & KRX 100 & -53.1942 & -3.4324 & -2.8623 & -2.5672 & 0.0001 & 1.9991 \\
\hline & Taiwan & TAIEX & -51.0115 & -3.4324 & -2.8623 & -2.5672 & 0.0001 & 1.9987 \\
\hline
\end{tabular}

As per the consequences in table 3designatesthat the unit-root does not exist in the levels of all indices. Considering the circumstances of East and South Asian nation's stock indices, the one-sided p-values of the individual index is below 5percent (specifically $0.01 \%$ ). Consequently, the null hypothesis of the existence of unit root is precluded at a level representing stationarity. The stock indices of East and South Asian are integrated at a level with logarithmic natural returns of each index (MacKinnon, 1996).

Furthermore, the null hypothesis for the ADFtest deliberates that the data has a unit root. The calculated ADF statistics for BSE Sensex (-57.0095), DSEX(-50.5698), S\&P Sri Lanka 20 Index(-41.2441), KSE 100 Index(-46.5623), SSE Composite(-24.8346), S\&P HKEx Large Cap
(-54.8119), Tokyo Topix (-53.7515),KRX 100(-53.1942) and Taiwan Capitalization Weighted Stock Index(-51.0115)that all are less than the critical value $(-3.4324,-2.8623$, and-2.5672 at 1percent, 5percent and 10 percent, respectively) as a result, H01is rejected. This confirms that East and South Asian indices returns are stationary and acquired a unit root.

\section{FINDINGS OF STUDY}

The stock indices return with WMA and EWMA are also evaluated for the mentioned period of study, which shows the following trend. 


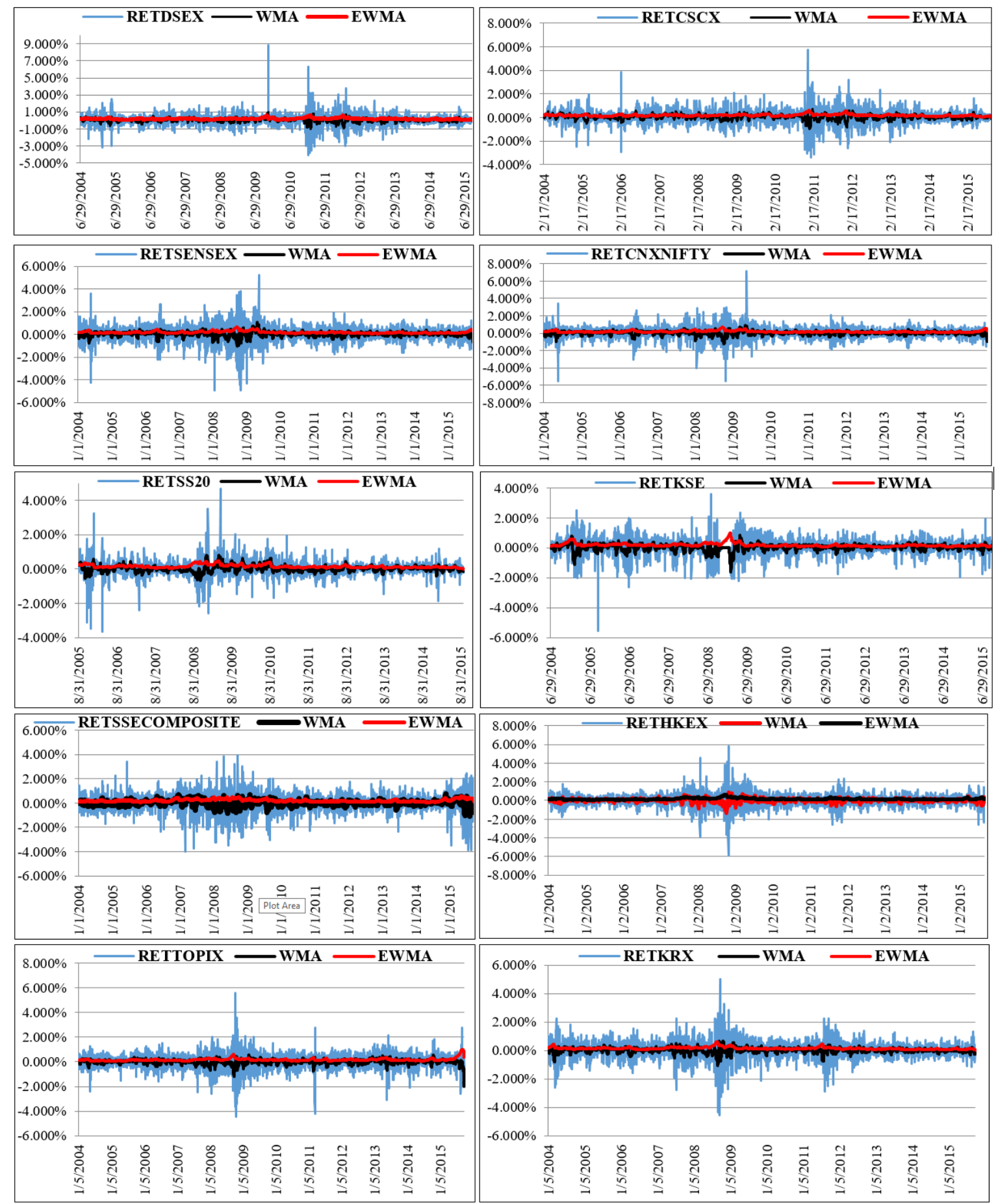

Figure: Stock indices return with WMA and EWMA

The researchers have realised the GARCH Model and Volatility Spillover for various stock indices.The analysis of data provides insights to the volatility of return on residuals

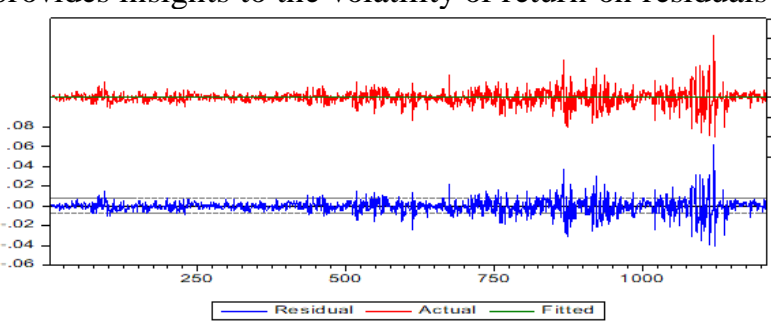

of DSEX, Sensex, KSE, SS20, SSE COMPOSITE, HKEX, TOPIX, KRX and TAIEX with the findings of the study.

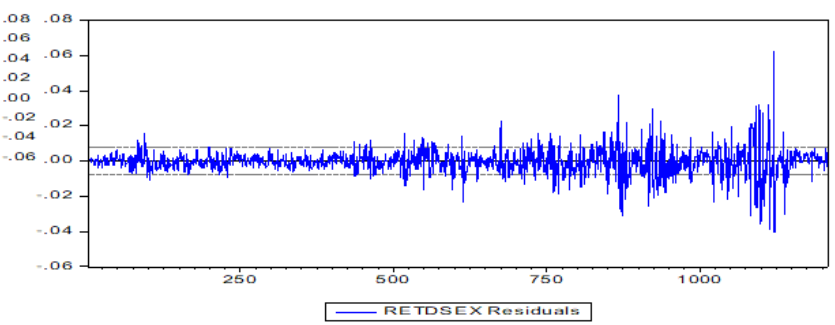

Graph 1: Volatility of return on DSEX Residuals

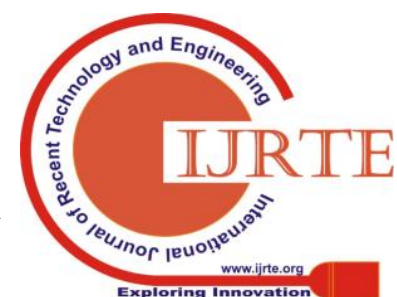



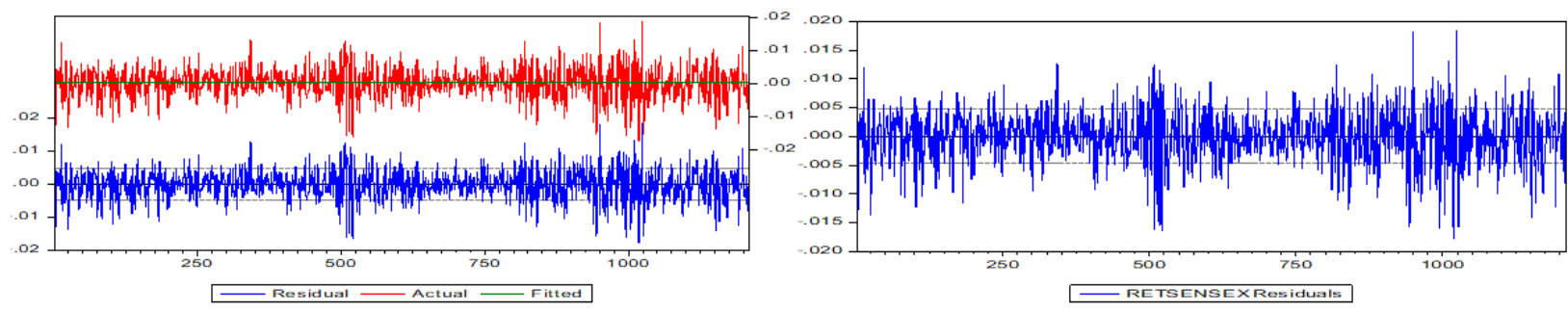

Graph 2: Volatility of return on BSE Sensex Residuals
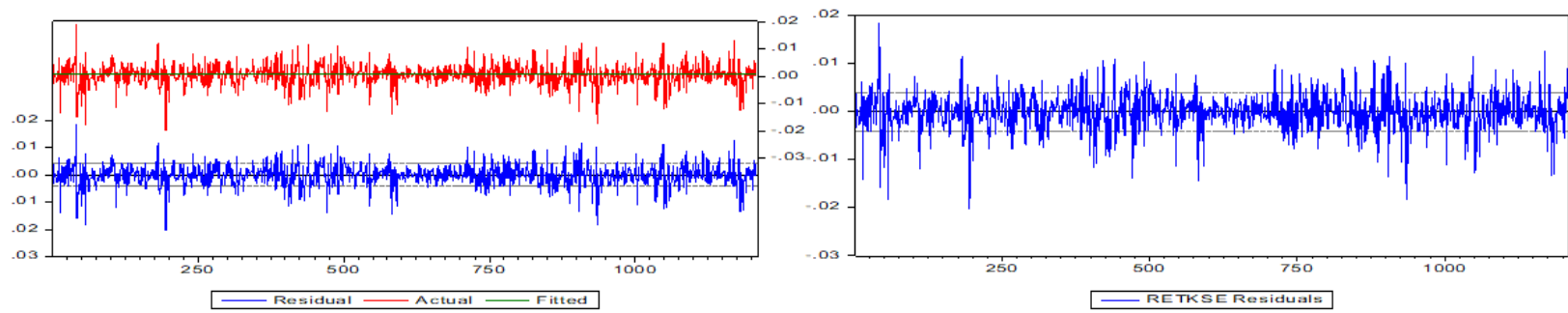

Graph 3: Volatility of return on KSE Residuals
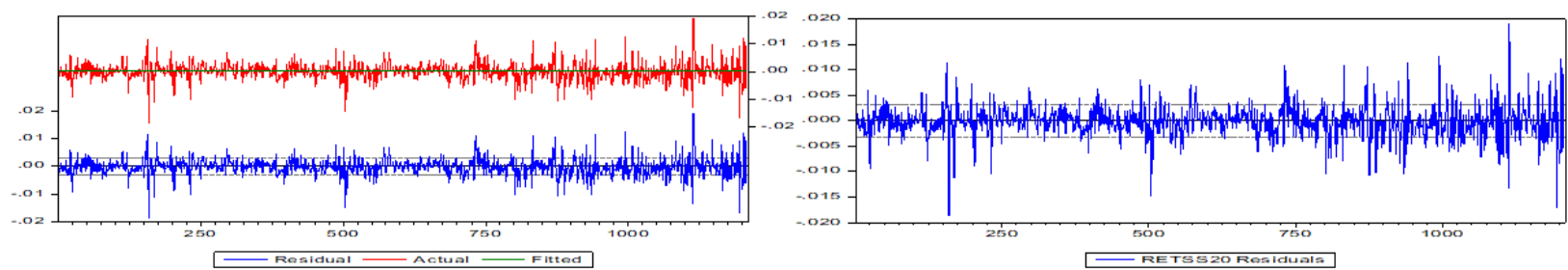

Graph 4: Volatility of return on SS20 Residuals
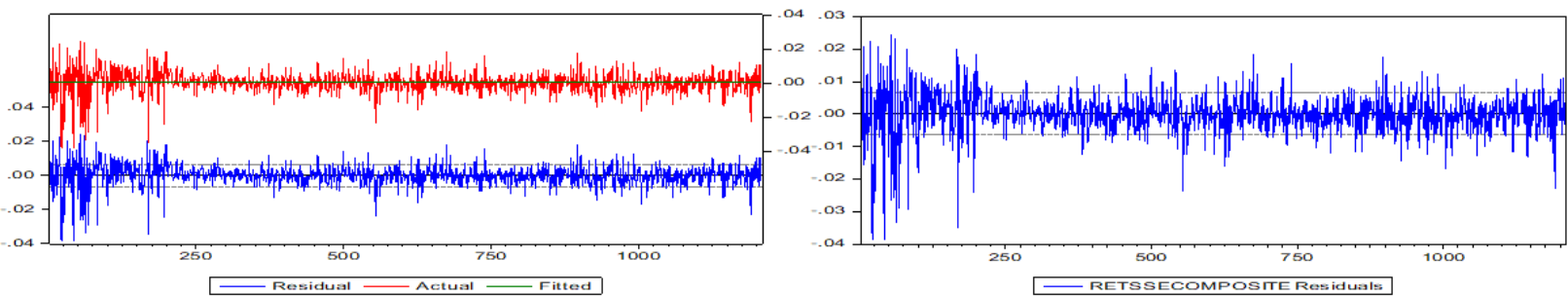

Graph 5: Volatility of return on SSECOMPOSITEResiduals
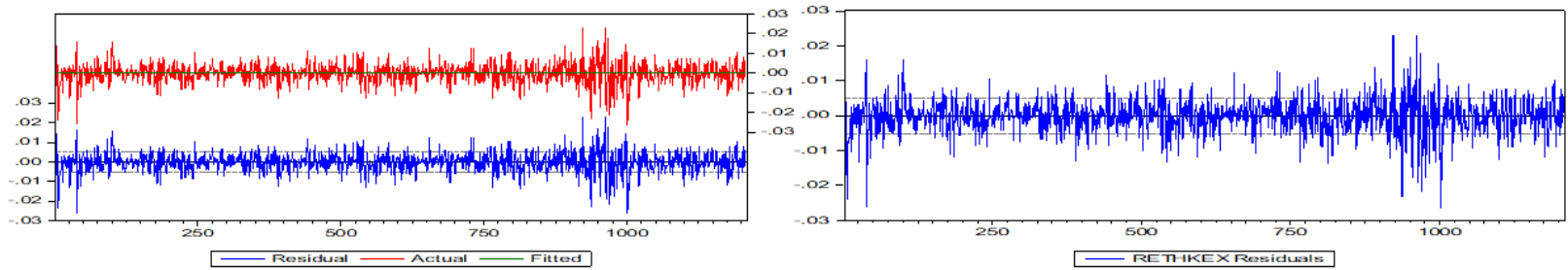

Graph 6: Volatility of return on HKEX Residuals
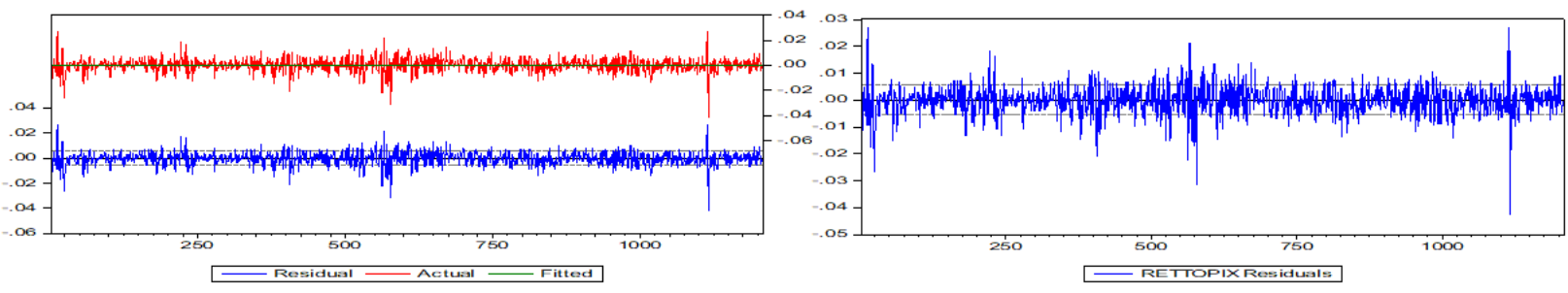

Graph 7: Volatility of return on TOPIX Residuals 

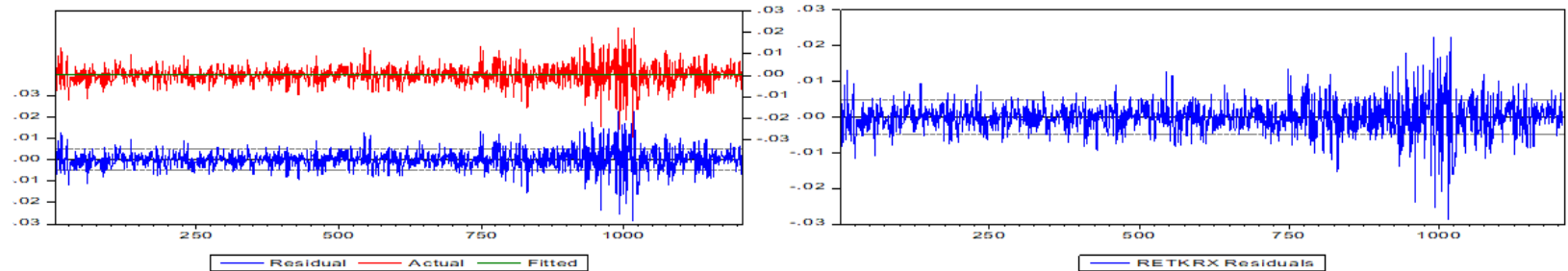

Graph 8: Volatility of return on KRX Residuals
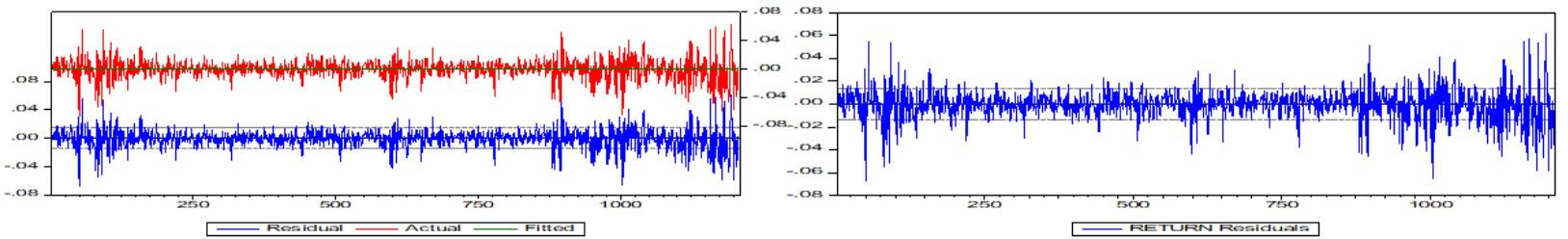

Graph 9: Volatility of return on TAIEX Residuals

This study emphasised the impact of combined and individual periods. It includes the whole-time phase (from 2004 to 2015), pre-financial crisis phase (from 2004 to 2007), financial crisis phase (from 2008 to 2011), and post-financial crisis phase (from 2011 to 2015).The educated guess for the effect of U.S.A. news is evaluated using the GARCH Model and volatility spillover.The coefficient of the autoregressive conditional heteroskedasticity $(\mathrm{ARCH})$ and the generalised autoregressive conditional heteroskedasticity (GARCH) (coefficients of $\alpha$ and $\beta$ ) are noteworthy. It discloses the perseverance of data end product on the equity earnings volatility. The ARCH coefficient $\left(\alpha_{1}\right)$ is near to the ground specifies not as much of waves of preceding news or events, reverse ARCH coefficient $\left(\alpha_{1}\right)$ is high specifies further waves of preceding news or events.

The significance of GARCH coefficient $\left(\beta_{1}\right)$ in the mentioned period specifies that the volatility of equity earnings is higher because of earlier earnings. It also defines the growing consequence of past news in the volatility of the stock price. The sum of ARCH and GARCH coefficient $\left(\alpha_{1}+\beta_{1}\right)$ is near to one for the period representing high or low perseverance of stock return volatility. The higher values of coefficients of $\alpha$ and $\beta$ suggests longer retention in the equity market. The output data variance is long-lasting and will receipts an extended time in the markets.

The coefficient of SS20 index earnings is near to the ground. The ARCH coefficient $\left(\alpha_{1}\right)$ is higher in all periods which is evaluated by Gaussian technique $(0.261590)$. The higher value of GARCH coefficient $\left(\beta_{1}\right)$ shows that the volatility of equity returns is higher in China, Hong Kong, Korea, Taiwan, Japan and India during this period. It also pronounces the cumulative effect of older news on the stock price volatility. However, the influence of the U.S.A. news is not significant on the volatility market returns of Bangladesh, Sri Lanka and Pakistan. In general, the equity markets in India (South Asia), China (East Asia), and Taiwan (East Asia) have higher variations in the study period.

China is the biggest exporter and hasa presence in markets all over the world. In the year 2007, there was a sudden volatility change due to market credit, privatisation of organisations and spreading out of their equity. On the other hand, this change in the volatilityof China is close to that of the United States and the markets of Japan and the U.S.A.are correlated with each other. Furthermore, the effect of market volatility of Bangladesh reflected at the Dhaka Stock Exchange (DSE), and Chittagong Stock Exchange (CSE) in September 2009 highlighted that the Bangladesh market is exposed to volatility dueto internal news, the orientation of industry, incidences of trade, and political situation, news or events. In the meantime of 2008 and after the U.S.A. financial crisis, it shows that the news or event is an outlier in the GARCH model. It shows that markets of Southeast Asian countries are less sensitive markets to the world-wide or U.S.A. news or events.

\section{CONCLUSION}

It is seen that the recent financial crisis of the U.S.A. stock market significantly affected the East and South Asian equity market, specifically Chinese, Indian, Japanese, and Korean equity markets. On the other hand, some other East and South Asian nations like Bangladesh, Sri Lanka, Pakistan, and Hong Kong stock markets are least affected by the global financial crisis. There are two models GARCH and ARCH are introduced to examine the stock market volatility, and value effect and both the models successfully prove the rising effect of old news coming from the U.S.A. stock market in East and South Asian stock return volatility. Though the Chinese economy is affected by the global financial crisis, they are trying to protect from this crisis by their robust banking sector. This study shows the global financial crisis is happened because of the good or bad information approaching from the U.S.A. stock market which has a significant effect on East and South Asian stock market returns because of the overflow of some information from the U.S.A. markets. The investors like the domestic institutional investors (DII) as well as foreign institutional investors (FII), who are looking for diversification of the portfolio, can associate these findings. FIIs prefer short term returns, and they are interested in high degree volatility of the stock market. As it is impossible to gain such high returns without causing volatility, FIIs are looking forward to these speculations. Subsequently, as per the outcomes of the study, domestic institutional investors and mutual funds can take help to study the drive of foreign institutional investors and carefully observe the effect on East and South Asian indices to design their plans for market

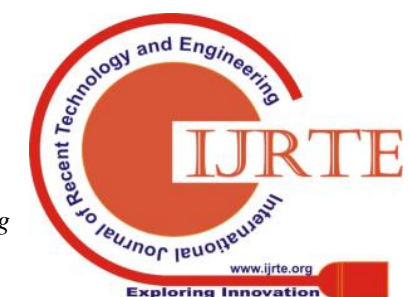


investment. While foreign institutional investors sell their shares, the domestic institutional investors and mutual funds start buying the stocks. This shows that domestic institutional investors are involved in capitalizing in a down market to proceeds benefits of stock returns volatility. Though the withdrawal of foreign institutional investors hurts the stock market, the instability of the equity market controlled this inequity. Finally, it can be stated that the present inequity in the stock market is found because of the old news from the U.S.A. stock market volatility which can also be used to know the upcoming stock volatility in East and South Asian stock markets.

\section{REFERENCES}

1. Aggarwal, R., Inclan, C., \& Leal, R. (1999). Volatility in emerging stock markets. Journal of Financial and Quantitative Analysis, 34(01), 33-55.

2. Bekaert, G., \& Harvey, C. R. (1997). Emerging equity market volatility. Journal of Financial Economics, 43(1), 29-77.

3. Bollerslev, T. (1986). Generalized autoregressive conditional heteroskedasticity. Journal of econometrics, 31(3), 307-327.

4. Chiang, T. C., Jeon, B. N., \& Li, H. (2007). Dynamic correlation analysis of financial contagion: Evidence from Asian markets. Journal of international money and finance, 26(7), 1206-1228.

5. Engle, R. (2002). Dynamic conditional correlation: A simple class of multivariate generalized autoregressive conditional heteroskedasticity models. Journal of Business \& Economic Statistics, 20(3), 339-350.

6. Groenewold, N., Tang, S. H. K., \& Wu, Y. (2003). The efficiency of the Chinese stock market and the role of the banks. Journal of Asian Economics, 14(4), 593-609.

7. Hammoudeh, S., \& Li, H. (2008). Sudden changes in volatility in emerging markets: the case of Gulf Arab stock markets. International Review of Financial Analysis, 17(1), 47-63.

8. Lim, K. P., Brooks, R. D., \& Kim, J. H. (2008). Financial crisis and stock market efficiency: Empirical evidence from Asian countries. International Review of Financial Analysis, 17(3), 571-591.

9. Liu, Y. A., Pan, M.-S., \& Shieh, J. C. (1998). International transmission of stock price movements: Evidence from the US and five Asian-Pacific markets. Journal of Economics and Finance, 22(1), 59-69.

10. Sakthivel, P., VeeraKumar, K., Raghuram, G., Govindarajan, K., \& Anand, V. V. (2014). Impact of Global Financial Crisis on Stock Market Volatility: Evidence from India. Asian Social Science, 10(10), 86-94.

11. Samarakoon, L. P. (2011). Stock market interdependence, contagion, and the US financial crisis: The case of emerging and frontier markets. Journal of International Financial Markets, Institutions, and Money, 21(5), 724-742.

12. Syllignakis, M. N., \& Kouretas, G. P. (2011). Dynamic correlation analysis of financial contagion: Evidence from the Central and Eastern European markets. International Review of Economics \& Finance, 20(4), 717-732.

13. Vento, G. A., \& La Ganga, P. (2009). Bank liquidity risk management and supervision: which lessons from recent market turmoil. Journal of Money, Investment and Banking, 10(10), 78-125.

14. Yilmaz, K. (2010). Return and volatility spillovers among the East Asian equity markets. Journal of Asian Economics, 21(3), 304-313. 